\title{
Marking Standing Trees with RFID Tags
}

\author{
Gianni Picchi $(\mathbb{D}$ \\ Consiglio Nazionale delle Ricerche-Istituto per la Bioeconomica (CNR-IBE), via Madonna del Piano 10, \\ 50019 Sesto Fiorentino, Italy; gianni.picchi@cnr.it
}

Received: 29 December 2019; Accepted: 27 January 2020; Published: 29 January 2020

\begin{abstract}
Precision forestry and traceability services for the certification of timber products require reliable systems for the identification of items throughout the supply chains, starting from the inventory of standing trees. AutoID systems based on radio frequency identification (RFID) are regarded as the most promising technology for this purpose. Nevertheless, there is no information available regarding the capacity of RFID tags to withstand the climatic and biological wearing agents present in forests for long periods, while maintaining the stored information and the capacity to return a readable signal over time. In order to assess this aspect, seven RFID UHF tags, selected from the range of commercial models or developed for this purpose, were used to mark standing trees for two years. Results showed that all models proved able to maintain sufficient operative capacity to be identified with manual (proximity) readers. Some models suffered damage to the protective case or were deformed, with a strong decrease in readability. Tags with simple structure and lower cost proved strong enough to endure one year without major drawbacks, and could be best suited for deployment in integrated auto-ID supply chains if used as disposable components. More complex and expensive tags are best suited for long-term marking, but application on living trees requires specific solutions to prevent damage due to stem growth.
\end{abstract}

Keywords: RFID tags; tree marking; forest inventory; certification; timber traceability; cost

\section{Introduction}

Automatic identification (auto-ID) technologies are becoming increasingly common in commercial applications. The uses range from industrial warehousing and logistics to agricultural and livestock management [1,2]. In forestry, they can provide support to the application of certification schemes enhancing the traceability of timber products [3]. For forest enterprises, an efficient traceability system is a major advantage not only for the related market benefits, but also for the improvements and cost reductions in the management of logging operations, stock movements, logistics, and invoicing [4], particularly if associated with counterfeit-safe info-tracing systems such as those based on blockchain technology [5].

On a wider scale, the growing attention towards the application of sustainable forest operations (SFO) requires full control of the supply chain and the related planning tools [6]. The technologies for the unique identification and auto-ID of trees, logs, and timber products may be essential for the implementation of precision forestry practices, the application of which is expected to exponentially increase in the near future, boosted by the rapid development of sensing technologies [7].

Among the different alternatives for auto-ID data transmission, radio frequency identification technology (RFID) is regarded as the best solution because of a number of advantages - painted codes or logos may wear out due to weather exposure over time [8]. Furthermore, compared to manual systems, tags readable at a distance avoid human errors in copying or noting, simplify the operation, and drastically reduce recording time [9]. QR and barcodes require proper illumination and a precise line of sight, and may be hidden by mud, dirt, or resin, all limits not present in RFID reading systems [10]. 
These already have a wide range of applications in the fields of logistics, livestock, and warehouse management, among others [11,12]. RFID technology provides different performances according to the operating frequency deployed. For the specific requirements of forestry, Ultra-High-Frequency (UHF) tags appear to be the most promising. In fact, this system operates at a frequency of $868 \mathrm{MHz}$ (in Europe), which allows for the maximum reading range among the commercial RFID types. According to the EPC standard, RFID tags have an internal memory which allows a content of 96 bits (EPC Class 1), including a string of 14 characters, providing a unique ID to each tag. Such information can be used to automatically tag an item (log or tree) on a digital database.

In forestry applications, RFID technology has been mostly tested for the control and optimization of timber logistics [13]. Another promising area for application is the traceability of timber throughout the whole supply chain, where the use of RFID for log marking may increase the level of automation of the log inventory, reduce the need for repeated measurements of the timber, and increase the overall efficiency, with evident economic benefits [14]. For this purpose, it is essential that RFID provide reliable and stable transfer of information throughout the whole supply chain. Tests performed in timber logistics have proven that this technology is mature, and that in the appropriate conditions, tags may be read even at relatively long distances (2-4 meters), despite the fact that in previous studies, bulk reading of incoming trucks loaded with tagged logs returned read rates of up to $92 \%$ at mill gate entrance [15]. Björk [16] claims that an economic benefit can be detected along the supply chain even with partial tagging of the whole load of logs, which still allows for a certain degree of traceability of the loads. This would also make the impact of a low automated read rate and physical survival rate less critical. Nevertheless, the potential of any auto-ID systems can be fully expressed only if very high reliability is achieved, and when RFID tagging is used as a link between physical items (trees) and digital inventory systems generated with the support of aerial and terrestrial sensors [17]. In this case, the manual identification of trees may provide further support to precision forestry applications in areas where global navigation satellite systems (GNSS) cannot be used with adequate accuracy, a relatively frequent occurrence in forests, particularly in mountainous areas [18].

The RFID tagging system has been proven to be able to resist the harsh conditions of timber hauling, at least in the case of cable yarder extraction [10], but the reliability of this marking system on standing trees is still unknown, particularly when tags are supposed to maintain their integrity and functionality over years of exposure to weather and adverse climate conditions. This would be the first step towards a fully mechanized auto-ID supply chain based on intelligent processor heads capable of reading the RFID tags on standing trees and marking each log while processing. Although no commercial machine currently features such capabilities, advanced prototypes have been demonstrated, integrating RFID auto-ID systems with sensors for log quality detection [19] and providing an extended tracking and tracing service by linking automatically determined quality parameters to the logs produced.

In a recent study, Kaakkurivaara tested the endurance of RFID tags to the outdoor conditions of a forest supply chain in tropical climates by recreating in the laboratory the factors considered the most challenging, such as high temperatures [20]. The study proved that climate factors can easily deteriorate the protective capsules of some RFID models, reducing their operative capacity and overall reliability. Clearly, a laboratory test can only simulate the factors involved, not capture the influence of their interaction (e.g., exposure to sunlight coupled with high temperatures) or consider unexpected factors arising from the complexity of the forest environment. Thus, a long-term experiment carried out on living trees in real forest conditions is necessary to assess whether RFID tagging systems are reliable enough to be deployed as an additional component of precision forestry practices and digital forestry inventories.

Against this background, a two year study comparing several RFID UHF tags was planned, involving the marking of standing trees with the aim of linking digital information and cutting instructions to the plants and maintaining it over time. The main purposes of the test were to 
- Assess the capacity of commercial or purpose-made RFID UHF tags to endure long-term deployment as marking tools attached on living standing trees;

- Compare different application systems and positions on the bark or wood;

- Assess the benefits of expensive, reusable tags against cheaper, disposable models.

\section{Materials and Methods}

The basic structure of the RFID tag is the transponder, a metallic element built in different shapes depending on its purpose and the manufacturer, and the integrated circuit. These elements are fixed on a simple plastic tape structure (possibly with one adhesive surface for application), or protected and supported with different type of cases, depending on the final application. The complexity of the final RFID structure is reflected in the size and the unitary cost.

RFID UHF tag models to be tested were selected from among the existing commercial products by comparing a considerable number of datasheets. At present, there are no commercial products specifically designed for marking trees; thus, the selection criteria was discussed with electronic engineers, logistics experts, and foresters. The main aspects considered were:

- the capacity to be identified at relatively long distances or in difficult conditions, in view of the deployment of a fully mechanized auto-ID system;

- the possibility to adapt the same tag to both manual and mechanical positioning;

- $\quad$ small size and low weight;

- waterproof enclosure.

As a result, six commercial tag models were chosen. Additionally, a prototype was created by enhancing a simple, short dipole tag model according to the comments of the professional foresters involved. The modification consisted of a simple plastic cover to protect the tag and enable stapling. The main characteristics of the seven tag models are reported in Table 1, while Figure 1 depicts their aspects.

Table 1. Technical characteristics of radio frequency identification (RFID) ultra-high-frequency (UHF) tag models used for the test.

\begin{tabular}{ccccccc}
\hline Code & Manufacturer & Model & Mass (g) & $\begin{array}{c}\text { Housing } \\
\text { material }\end{array} \mathbf{1}^{\text {Application }}$ & $\begin{array}{c}\text { Fixing } \\
\text { holes }\end{array}$ & (ccrew \\
OE & Omni-ID & Exo 600 & 12.5 & ABS & 2 & staple \\
HS & HID & Slimflex & 6.0 & TPE & 2 & screw \\
CI & Confidex & Ironside & 29.9 & TPE & 2 & screw \\
SY & Synometrix & SMLM-8200 & 18.2 & ABS & 1 & screw \\
CIM & Confidex & Ironside & 4.3 & TPE & 1 & staple \\
CP & Confidex & Pino & 0.6 & PET & 0 & staple \\
SS & Smartrac & Shortdipole & 1.1 & PET EVA & 0 & \\
\hline
\end{tabular}

${ }^{1} \mathrm{TPE}=$ Thermoplastic Elastomer, $\mathrm{ABS}=$ Acrylonitrile Butadiene Styrene, $\mathrm{PET}=$ Polyethylene terephthalate, EVA = Ethylene Vinyl Acetate. 


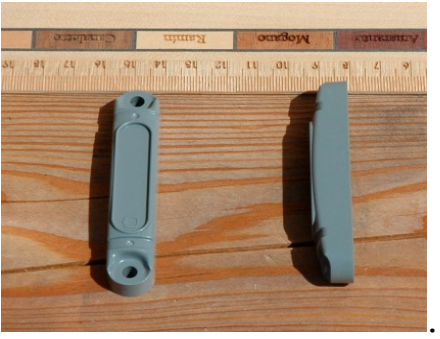

(a)

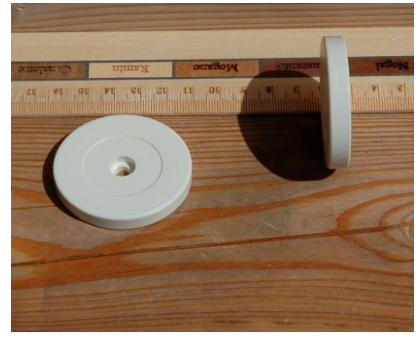

(d)

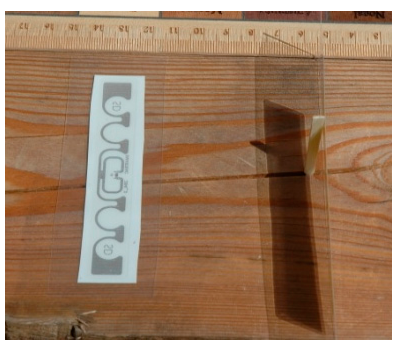

(g)

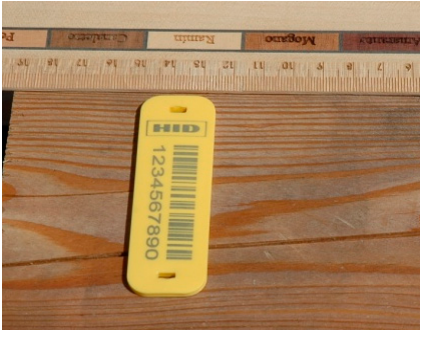

(b)

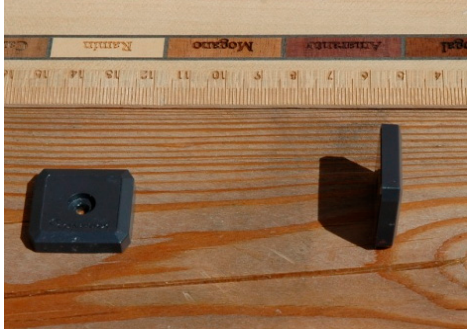

(e)

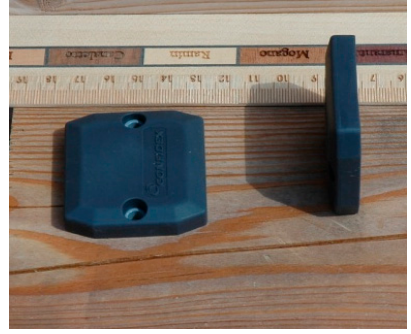

(c)

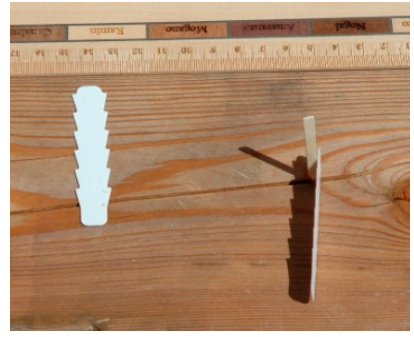

(f)

Figure 1. RFID tags used to mark standing trees: (a) OE, (b) HS, (c) CI, (d) SY, (e) CIM, (f) CP, (g) SS.

Sample tags were provided by local resellers according to their stock availability, leading to an unbalanced number of tags per model. Nevertheless, given that all the selected tags were considered significant to the study, even those provided in very limited numbers were deployed. In addition to the test material, dealers were requested to provide an economic offer for their products according to three hypotheses of batch volumes: 5000, 20,000, and 100,000 units per batch. This allowed the calculation of unitary cost of tags according to use intensity. All the received tags were checked prior to application to verify their correct functioning and to acquire the factory-assigned ID, which was recorded in a database.

In July 2014, RFID tags were applied on the standing trees of a forest plot located in the eastern Italian Alps, in the municipality of Sover, northern Italy. The plot, with an area of 5 hectares, was dominated by conifers (mainly Picea abies (L.) Karst.) and located on the north face of a steep valley at an altitude ranging from 880 to 950 meters above sea level. Overall, a total of 53 trees with average diameter at breast height (DBH) of $40 \mathrm{~cm}$ (totaling about $100 \mathrm{~m}^{3}$ in volume) were marked in about $2.5 \mathrm{~h}$. This time includes all marking, measuring, and recording operations, as well as moving within the steep plot. Almost all selected trees were Picea abies (L.) Karst., with the exception of some Abies alba Mill.

The test was performed during standard tree marking operations of a forest lot planned for harvesting, with selective cut mainly on mature trees, in the frame of a close-to-nature silviculture approach. The professional forester marked trees both with the traditional system and with RFID tags. In the eastern Italian Alps, the traditional marking system consists of debarking a couple of spots on the trunk and stump of the tree, creating spots visible from a considerable distance owing to the color contrast of bark (dark brown) and wood (pale yellow). RFID tags were applied to the trunk at 
about $130 \mathrm{~cm}$ height, in correspondence with the traditional mark. Two different fixing methods were used depending on the type of tag: (1) common steel screws driven into the bark/wood with a manual screwdriver or (2) aluminum staples applied with a staple gun (tacker). Tags were concealed as much as possible under the bark lifted by the traditional marking. This solution was considered useful to enhance the endurance of tags and to minimize their visibility. The latter was considered important given that in areas with relatively high human density (tourists, mushroom collectors, and hunters), highly visible tags would be prone to vandalism [8].

During the marking of trees, the relevant information of each tree was linked to the ID of the tag on a database with the same purpose-made Android application described by Pichler et al. [17] and a similar set of measurement tools. For this test, just DBH, tree species, GPS position, and notes on tree quality (e.g., bifurcations, resin emissions, etc.) were recorded.

Any observations made while marking the trees were noted in order to evaluate each tag model and the relative application method. Due to the preliminary stage of the system and the inexperience of the operator, no detailed time recording was performed.

Tags were controlled for the first time in August 2015, after one year of exposure to climatic (Table 2) and biological factors. Their operative capacity was checked in the forest by means of a portable RFID UHF reader. In the forest, it was difficult to define a measurement protocol applicable to all conditions (for instance, with a constant reading distance and angle); thus, the test consisted of gradually moving the reader nearer to the tag and reporting any apparent difficulties in detecting it. In case of successful tag detection, a second test was performed by re-programming the internal code. This second operation required a more stable connection with the reader. A tag that was detectable but not programmable would highlight a weak and erratic returned signal. Together with reading and programming controls, each tag was visually checked for any damage, deformation, or alteration that may have had an influence on the performance or usability of these identifiers.

Table 2. Main climatic data recorded by the weather station of Segonzano.

\begin{tabular}{cccccc}
\hline Period & Rainfall (mm) & $\begin{array}{c}\text { Mean Air } \\
\text { Temperature }{ }^{\circ} \mathbf{C}\end{array}$ & $\begin{array}{c}\text { Minimum air } \\
\text { Temperature }{ }^{\circ} \mathbf{C}\end{array}$ & $\begin{array}{c}\text { Maximum Air } \\
\text { Temperature }{ }^{\circ} \mathbf{C}\end{array}$ & $\begin{array}{c}\text { Mean air } \\
\text { Moisture (\%) }\end{array}$ \\
\hline $\begin{array}{c}\text { First year } \\
\text { 2014-2015 }\end{array}$ & 791 & 10.6 & -9.1 & 34.9 & 75.4 \\
$\begin{array}{c}\text { Second year } \\
\text { 2015-2016 }\end{array}$ & 635 & 10.6 & -11.2 & 32.2 & 75.4 \\
\hline \multicolumn{5}{r}{ Located about 7 km from the test site, at an elevation above sea level of 660 meters. }
\end{tabular}

Located about $7 \mathrm{~km}$ from the test site, at an elevation above sea level of 660 meters.

Tags were detected and programmed in the forest with a portable CAENRFID qIDmini reader with a linearly polarized antenna (horizontal) interfaced with a smartphone. Like any portable RFID device, the reader can operate with a maximum emitting power of $500 \mathrm{~mW}$. For the purposes of manual detection, where it was possible to move the reader near to the tag, this power emission already guaranteed effective reading at a distance of $0.8-1 \mathrm{~m}$ in optimal conditions. Nevertheless, for the test, the emitting power of the reader was limited to $140 \mathrm{~mW}$, for two reasons:

- $\quad$ avoiding multiple reading, for instance due to tags placed on neighboring trees;

- creating more challenging reading conditions that would better highlight malfunctions or loss of returned signal from the RFID tags.

The second year, in June 2016, tags were checked again for their operative capacity, visible damage, and any other relevant factors, such as presence of organic substances (e.g., resin). After the control, tags were carefully removed from the trees and brought to a laboratory, where their operative capacity was checked again in constant and controlled conditions. For this purpose, tags were placed flat on a dry wooden surface with the reader hanging perpendicularly from a distance of $10 \mathrm{~cm}$. Reading cycles had a duration of 3 seconds. In case of failure to detect the tag, the same test was repeated at a distance 
of $5 \mathrm{~cm}$. The quality of the returned signal was evaluated by means of the Received Signal Strength Indicator (RSSI). This is a value used in radio telecommunication to measure the power of the received signal, expressed in $\mathrm{dBm}$. In RFID applications, this parameter is used to measure the power of the signal received from the UHF RFID transponder. The higher the RSSI value, the stronger the signal received and thus the better the performance of the tag model.

\section{Results}

\subsection{Application in the Forest}

Fixing the tags on the trees was a relatively easy and fast operation, particularly when the stapling system was used. The application of tags with screws was more time consuming, particularly if two screws were inserted in the larger tag models, as a manual screw driver was used.

Applying tags in the spot previously debarked with the marking axe was simple, since a flat and clean surface was already available. In contrast, fixing the tags on the bark was impractical without previous preparation of the application spot, to remove the rough, unstable superficial layer. RFID tags with non-rigid shells, such as SS, CP, and HS, suffered deformation when applied directly onto the bark. This deformation altered the geometry of the transponder, which could not offer a flat surface to the waves emitted by the interrogating antenna, thus reducing the returned signal. The shape deformation was particularly evident with elongated tags applied with staples at both ends. Additionally, for this type of tag, the orientation of application also affected the capacity to return the signal to the reader. In fact, when applied adhering horizontally on the tree, the tags suffered a bending effect (Figure 2). During the field tests, it was observed that bended transponders were still operative, but application on trees with smaller diameters led to increased bending angles, which strongly decreased the returned signal. This drawback was not present in tags applied vertically, where no bending effect was detected.

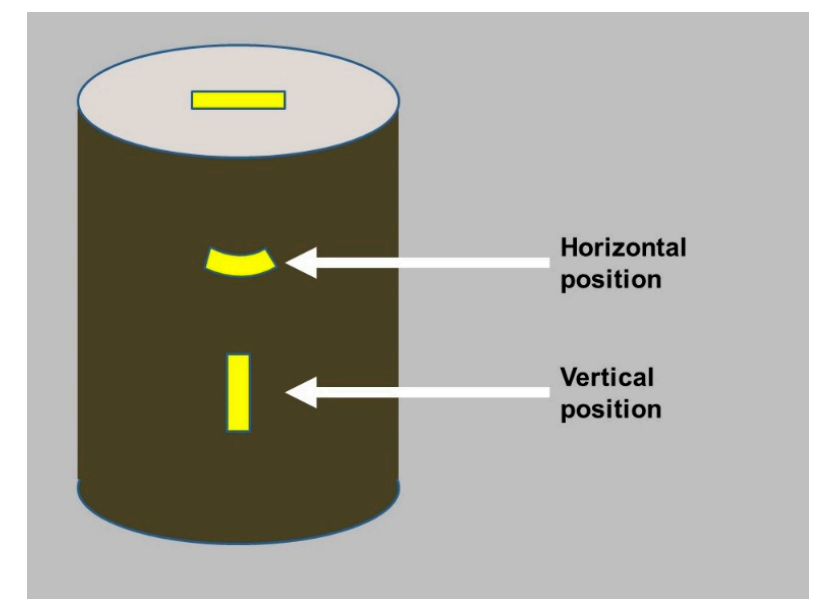

Figure 2. Positions of application of tags on the trunk of the tree. In case of logs or felled trees, tags could also be placed on the crosscut section.

\subsection{Resistance in the Forest}

After one year attached to standing trees, all RFID UHF tag models were operative (Table 3). The Confidex Pino (CP) model suffered a strong decrease in signal strength, due to the fact that the staples perforated the transponder structure. Some hard-shell models suffered damage to the case structure due to tree growth, but such damage did not seem to reduce the protective capacity of the shell. Another factor observed was the abundant resin emission in some debarked areas (where the tags were applied). The tags covered by resin appeared to have a weaker signal than clean tags, but this factor could not be quantified. 
Table 3. Operative conditions of tags after 1 year permanent installation in forest.

\begin{tabular}{|c|c|c|c|c|}
\hline Tag Model & $n$. Used & $n$. Tags Operative & $\begin{array}{l}\text { n. Tags Readable and } \\
\text { Programmable }\end{array}$ & Notes \\
\hline $\mathrm{CI}$ & 11 & $11(100 \%)$ & $11(100 \%)$ & \\
\hline $\mathrm{OE}$ & 10 & $10(100 \%)$ & $10(100 \%)$ & $\begin{array}{l}\text { Most of the cases were cracked at } \\
\text { the screwing area because of tree } \\
\text { growth. The tags were still well } \\
\text { fixed. }\end{array}$ \\
\hline SS & 13 & $13(100 \%)$ & $13(100 \%)$ & \\
\hline SY & 3 & $3(100 \%)$ & $3(100 \%)$ & \\
\hline $\mathrm{CP}$ & 3 & $3(100 \%)$ & $2(66 \%)$ & $\begin{array}{l}\text { Returned signal was very weak in } \\
\text { all tags. One had to be removed } \\
\text { and replaced as it was hardly } \\
\text { readable and not programmable. }\end{array}$ \\
\hline CIM & 12 & $12(100 \%)$ & $12(100 \%)$ & \\
\hline HS & 1 & $1(100 \%)$ & $0(0 \%)$ & $\begin{array}{c}\text { The tag was not programmable, } \\
\text { probably due bending of the } \\
\text { transponder. }\end{array}$ \\
\hline
\end{tabular}

After the second year, all tags were still operative and capable of returning a signal to the emitting antenna despite the low interrogating power used $(140 \mathrm{~mW})$. Damage to the case or protective layers due to tree growth was evident and, for some models, severe (Table 4). Resin had heavily covered the tags placed on the tree marking spot. In the case of the model SS, resin contact had clearly corroded the plastic cover, reducing its flexibility and integrity, while the tags of the same model not affected appeared undamaged.

Table 4. Operative conditions and general comments of tags after 2 years permanent installation in forest.

\begin{tabular}{|c|c|c|}
\hline Tag Model & $n$. Tags Operative & General Comments and Observations \\
\hline CI & $11(100 \%)$ & $\begin{array}{l}\text { The case could endure the strain without evident deterioration. Deformation } \\
\text { was frequent due to the tensions caused by stem growth. Metal screws were in } \\
\text { good conditions (one was broken, but not the plastic). }\end{array}$ \\
\hline $\mathrm{OE}$ & $10(100 \%)$ & $\begin{array}{l}70 \% \text { of the plastic cases were broken at the level of screw holes. } 50 \% \text { (five items) } \\
\text { had both screw holes broken and the tag was kept in position by the solidified } \\
\text { resin at the back surface of the tag. Only three tags were undamaged. }\end{array}$ \\
\hline SS & $13(100 \%)$ & $\begin{array}{l}\text { All tags were operative. Most of the tags were inserted under the bark or } \\
\text { stapled in two places. This lead to a slight deformation in shape for many of } \\
\text { them and a relatively weaker signal (see also suggestions for stapling } \\
\text { horizontally/vertically). Plastic was fragile and removal was difficult; in most } \\
\text { cases, it led to breaking the light "case". This could be an issue if long term } \\
\text { permanence is planned. In case of important supply chain information transfer, } \\
\text { the tags should be replaced or a different model should be preferred if marking } \\
\text { must endure for longer periods. }\end{array}$ \\
\hline SY & $3(100 \%)$ & $\begin{array}{c}\text { The case was intact, and the single screw was enough to hold the tag with no } \\
\text { damage due to tree growth. }\end{array}$ \\
\hline $\mathrm{CP}$ & $3(100 \%)$ & $\begin{array}{l}\text { Due to the design of this tag, it was very difficult to staple without touching the } \\
\text { transponder. In two cases, the transponder was clearly punctured. One tag had } \\
\text { to be replaced in } 2015 \text { due to the weak signal returned (although operative). } \\
\text { The second stapled tag was still operative in 2016, but with a limited returned } \\
\text { signal. The third tag was perfectly operative and readable under bark and } \\
\text { covered with resin emissions. }\end{array}$ \\
\hline CIM & $12(100 \%)$ & $\begin{array}{l}\text { A single fixing point again proved to be a good solution for minimizing the } \\
\text { tensions caused by the trunk growth. All of the tags were operative. Due to the } \\
\text { small size of the transponder, the signal for this tag was relatively low, but } \\
\text { reliable over time. }\end{array}$ \\
\hline HS & $1(100 \%)$ & $\begin{array}{l}\text { A single tag was available for this model. The flexible case could easily } \\
\text { accommodate the tree growth. On the other hand, this led to a twisting } \\
\text { deformation, which reduced the reading power (dispersion of returned signal } \\
\text { due to a non-flat transponder shape). The plastic was hardened and barely } \\
\text { flexible, but perfectly intact. }\end{array}$ \\
\hline
\end{tabular}


The tests in laboratory conditions confirmed that the tags were all fully operative, even with evident damage (Figures 3-6). Once the deformations due to tree growth were removed, some tags provided a better signal than on the standing tree. OE, HS, and SY models returned the strongest signal, with RSSI values above $-400 \mathrm{dBm}$. CIM and SS models returned the weakest signal, to the point that part of these tags could only be detected by the reader at a distance of $5 \mathrm{~cm}$ (Table 5).

Table 5. Laboratory reading performance of the tags after 2 years in the forest.

\begin{tabular}{ccccccc}
\hline Tag Type & $\boldsymbol{n}$. Tags & $\begin{array}{c}\text { Effective Reading } \\
\text { Distance }(\mathbf{c m})\end{array}$ & $\begin{array}{c}\text { Tags Detected per } \\
\text { Cycle }^{\mathbf{1}}\end{array}$ & SD & $\begin{array}{c}\text { Average } \\
\text { RSSI (dBm) }\end{array}$ & SD \\
\hline OE & 10 & 10 & 14.7 & 1.7 & -367.0 & 27.1 \\
HS & 1 & 10 & 13.0 & & -359.0 & \\
CI & 11 & 10 & 13.6 & 2.0 & -440.8 & 34.6 \\
SY & 3 & 10 & 13.0 & 0.8 & -365.7 & 24.9 \\
CIM & 7 & 10 & 13.3 & 2.4 & -481.9 & 22.5 \\
CP & 2 & 10 & 9.5 & 0.5 & -409.0 & 10.0 \\
SS & 10 & 10 & 12.3 & 2.5 & -445.0 & 63.9 \\
CIM & 6 & 5 & 10.3 & 0.7 & -405.7 & 18.9 \\
SS & 3 & 5 & 11.7 & 5.3 & -445.7 & 77.2 \\
\hline
\end{tabular}

Each reading cycle had a duration of about 3 seconds. This value indicates how many times the tags have been detected by the reading reiterations. RSSI value is returned as a negative figure; thus, values closer to zero indicate a better signal.

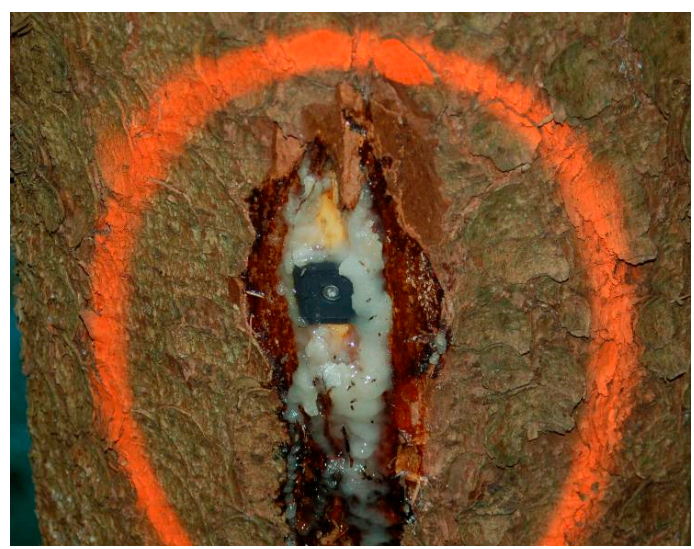

(a)

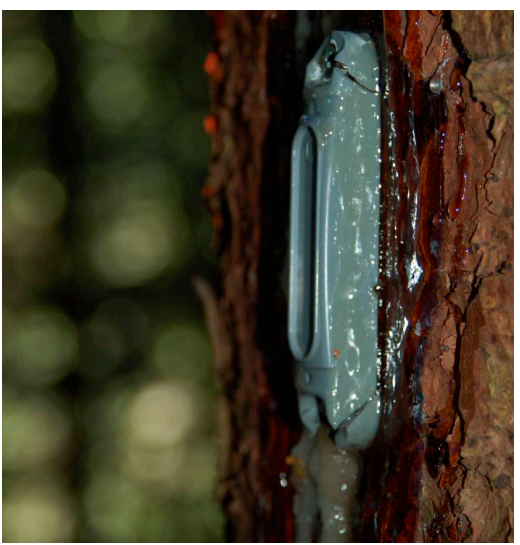

(b)

Figure 3. (a) CIM model and (b) OE model after 2 years. Note the cracks on the case of OE tag.

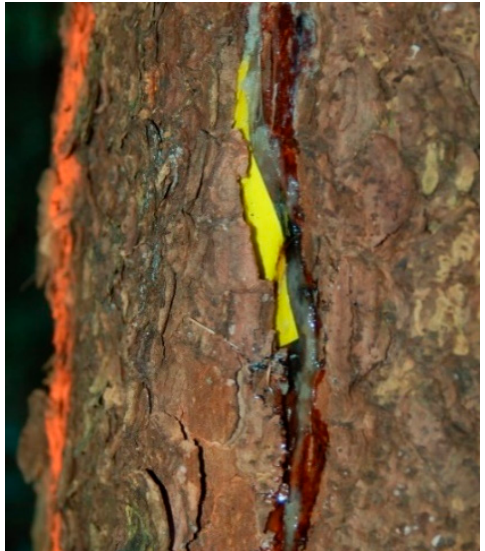

(a)

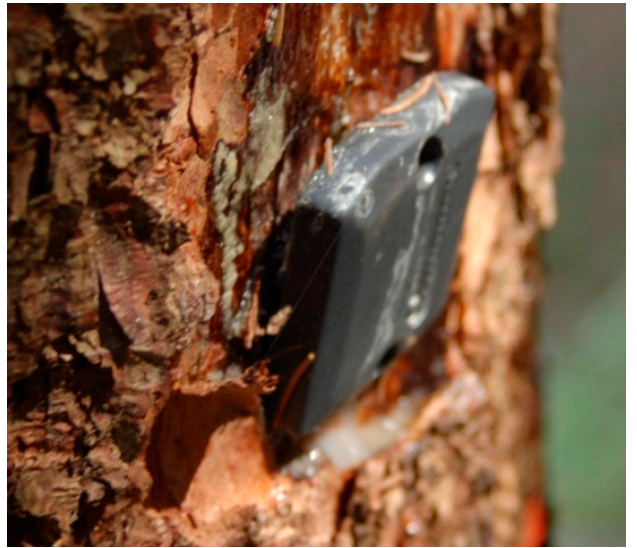

(b)

Figure 4. (a) SS model and (b) CI model after 2 years. 


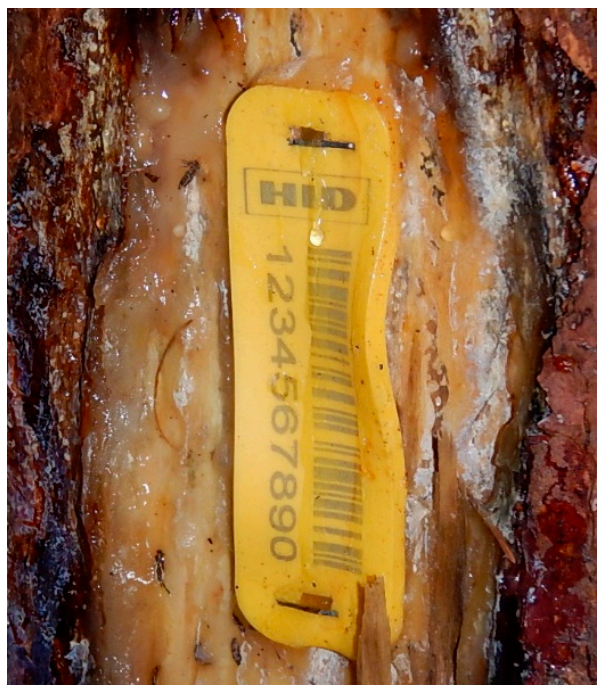

(a)

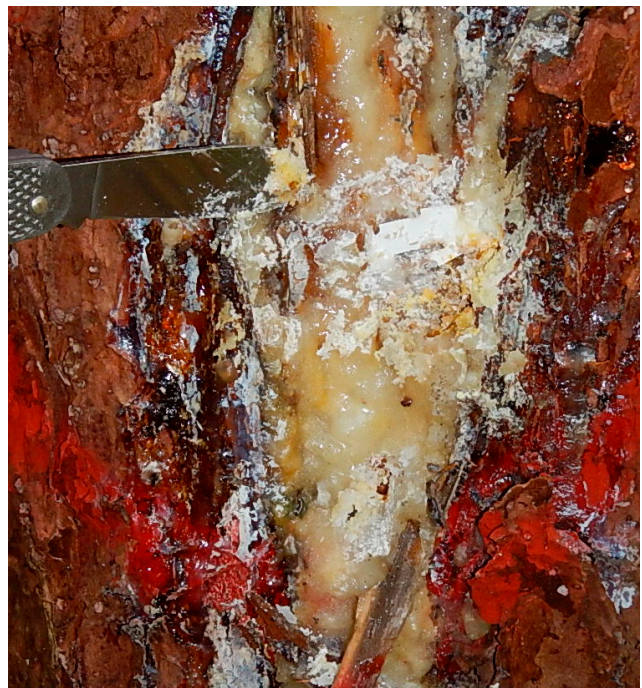

(b)

Figure 5. (a) HS model and (b) CP model after 2 years. Note how the first has bent due to tree growth and the latter is covered by resin.

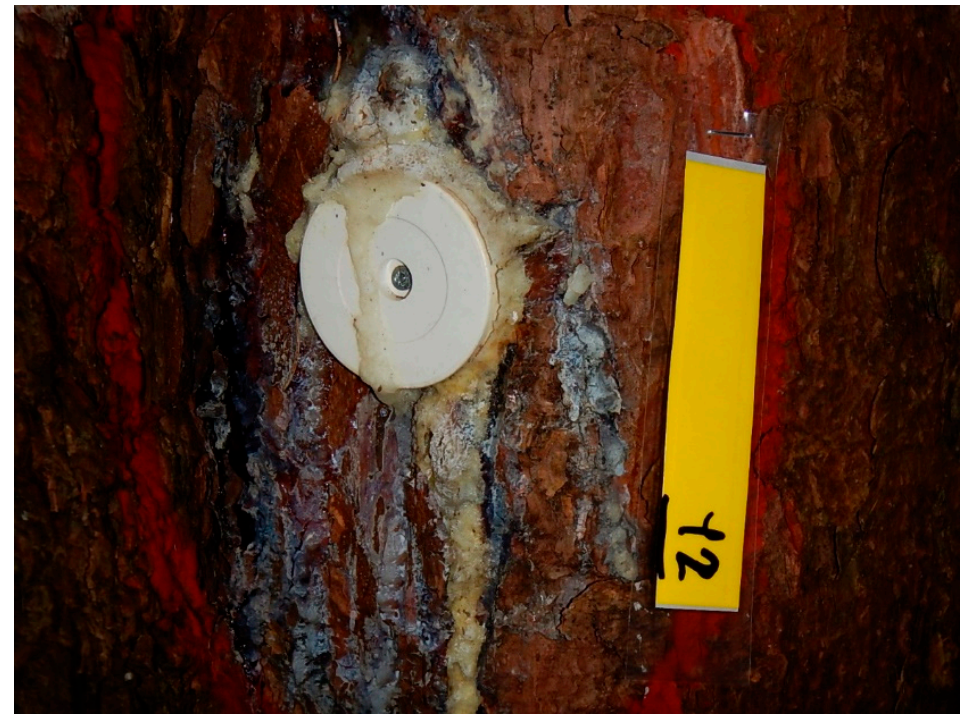

Figure 6. SY model (left) after 2 years and a newly applied SS tag over bark (right).

\subsection{Cost of Tags}

The cost of the tags depended on the complexity of the protective case (Figure 7). Heavier, more complex industrial tags always have a unitary cost above $1 €$. Simple tags such as CP and SS have a much lower cost, which decreases to below $0.5 €$ when larger batches are purchased. This is a general rule that can be observed with all tag models. Nevertheless, the trend is not equal for all tag models, being linear in some cases and power type for most of the offers received. As a result, the benefits of increasing the number of tags purchased differed according to the tag model (or dealer). 


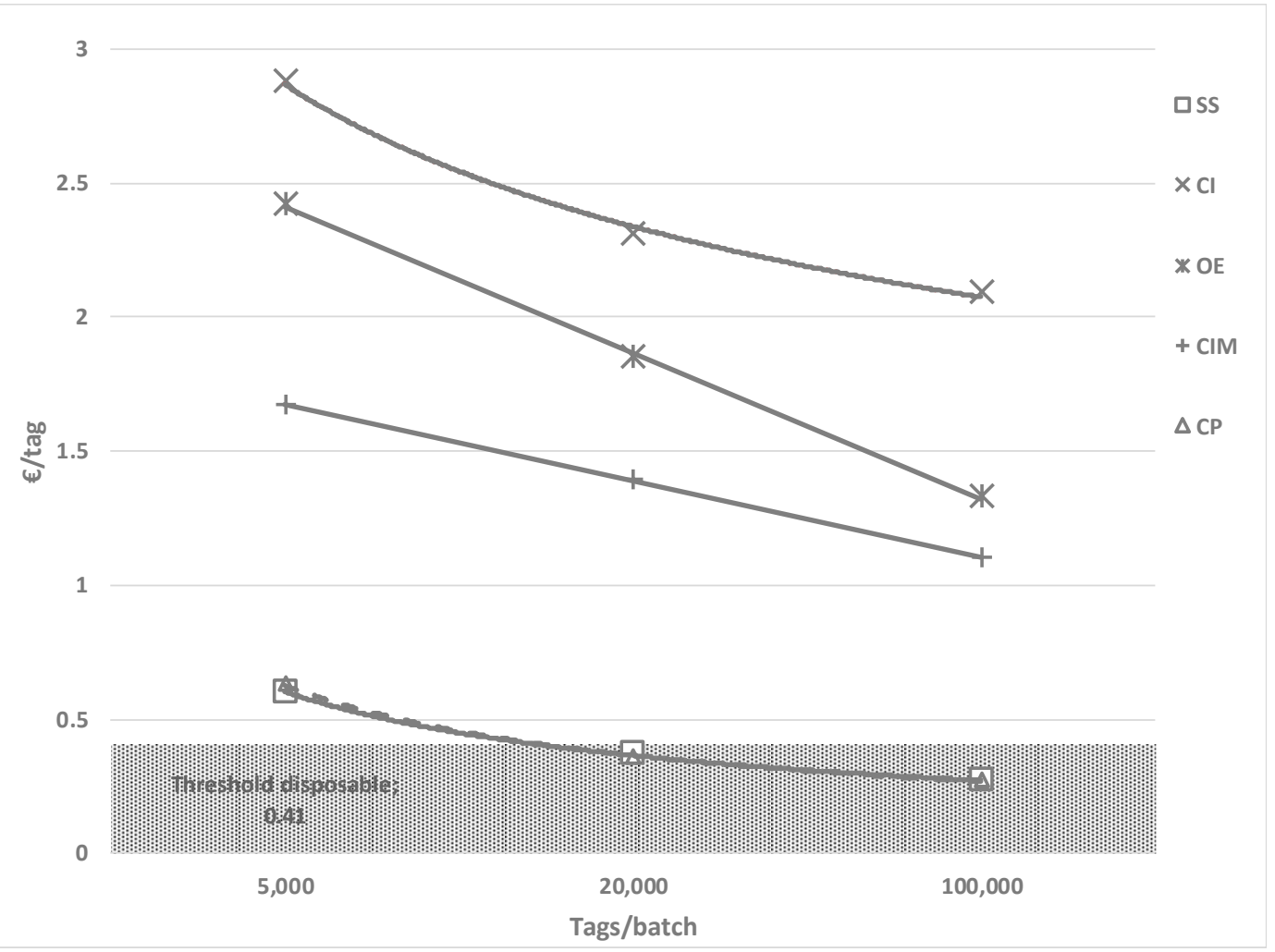

Figure 7. Unitary cost of different RFID UHF tag models according to the volume of the purchased batch.

\section{Discussion}

The tested RFID UHF tags were suitable for marking standing trees and relating the physical items to the digital forest inventory database. Tags requiring a screw to be fixed to the tree were less suitable, demanding more time and equipment (screws, screwdriver). Furthermore, the use of steel screws was limited by the fact that manual removal from the timber was not easily and automatically feasible. Non-metal resin screws could be deployed, although these entailed pre-drilling a hole to drive the screw into the wood, requiring extra labor during forest marking and additional equipment for the forester.

In the case of flexible tag models, the application procedure proved to be particularly relevant. Prior to the application of the tag on the bark, the main irregularities were flattened off by means of a sharp tool or a hard object (the metal edge of the stapler used in the tests proved to be enough for this treatment). Clearly, this issue will be more important on trees with thick and irregular bark (e.g., most conifers, oaks) than on species with smooth bark (e.g., beech). Additionally, any position that forces the tag to follow the circumference of the tree should be avoided. This is particularly relevant with small diameter trees, but in any case it is always advisable to place tags vertically on the trunk, avoiding any bending to the transponder.

All tag models could endure long term permanence in the forest while maintaining their operative capacity. Climatic factors did not seem to cause an excessive strain to the protective case of tags, even with the most simple models. This may also have been due to the fact that in dense forest stands, with continuous cover, tags placed at the base of the standing tree were not exposed to extreme variations in temperature and light as they would have been in an open field. During their permanence in the forest, tags were challenged mainly by unexpected factors, namely tree growth and resin emission. Tree growth had different consequence depending on the type of tag case.

- Hard-case models suffered increasing tension due to diameter increase of the tree. The strain was much stronger on tags secured with two screws, which were unable to accommodate the trunk 
variations. Out of this group of tags, CI suffered little damage due to the robust and relatively flexible case, while OE showed cracks on most of the insertion holes. Damage did not alter the reading capacity of OE tags, but did make their permanence on the tree unreliable (most tags only remained on site due to the abundant presence of resin). Hard-case models fixed with a single screw could better adapt to tree growth, even if some case deformation could be observed in CIM tags.

- Tag models with simple and flexible cases could adapt their shape to the tree growth, presenting no evident damage due to this factor. Nevertheless, this phenomenon lead to deformation of the tag and the enclosed transponder antenna suffered twisting or bending, clearly reducing the reading capacity of the tags. This outcome was more evident in SS and HS tags, attached with staples at both ends. SS and CP tags fixed with a single staple with freedom to move did not suffer a decrease in their readability. Resin seemed to alter the properties of the simple PET EVA enclosure of SS tags. In fact, after 2 years installation in the forest, the SS tags abundantly covered by resin were clearly more fragile than the others. This could reduce their reliability in subsequent operations, if the same tag is expected to endure tree felling and hauling. Furthermore, damage to the protective layers turned brittle by the resin made manually removing the tag prior to felling the tree and stapling it back at the crosscut section impractical. In such cases, the tag should be read and coupled with a new one to be placed on the felled tree.

Removing transponder deformation and resin cover in the laboratory proved that most tags had fully maintained their capacity to return a clear signal, even in the case of severe damage to the case. Only some of the SS and CIM models presented permanent deformation of the transponder, which led to weaker signals and a reduced reading capacity, below $-450 \mathrm{dBm}$ when exposed to an interrogating power of $140 \mathrm{~mW}$.

Hard-case models proved more reliable over time, but the unitary cost was always well above the economic threshold of $0.41-0.35 €$ identified by some authors $[9,21]$ for an economic implementation of disposable RFID tags in forest supply chains. This cost barrier could be only met by simple tag models if purchased in batches of 20,000 units or larger.

In timber supply chains, one of the main obstacles to the implementation of marking systems in general is the specific requirements of the end users. In fact, sawmills do not accept timber with attached elements that could damage the sharp tools used in the industrial process (saws and knives). Furthermore, tags attached to the log surface would end up together with slabs and edgings in the stream of processed wood chips, the typical byproduct of sawmills, which is used either for pulp or energy production. In both cases, the presence of contaminants such as plastic or metal could limit or even prevent the viability of this material. Pulp industries have strict quality requirements in this sense. For this reason, care should be taken with the unitary mass of the tag model, which may vary greatly (from about $1 \mathrm{~g}$ to over $20 \mathrm{~g}$ ) and the housing material used for the construction of tags. Some manufacturers provide tags made with organic plastics which dissolve when exposed to the alkaline or acid solutions used in pulp industry. Suitable materials for the casing of RFID tags could be, for instance, PLA plastics (polylactic acid), even if their capacity to endure open air conditions should be carefully tested.

In the case of manual identification of RFID tags on standing trees, positioning the reader at minimum distance, perpendicularly to the tag assured a $100 \%$ reading rate. If manual felling is performed, the RFID tag originally placed on the standing tree should be moved to the crosscut section (or paired with a new tag in this position). The crosscut section provides the most reliable reading conditions, and is more protected during hauling, reducing the risk of accidental removal of the RFID tag from the tree. The same position should be chosen for the logs processed from the tree in order to facilitate the bulk reading of RFID tags on the timber transported and piled during the logistic and storage operations. These repositioning operations are difficult to implement if a fully mechanized supply chain is deployed, from felling to delivery at mill gate. Further research is needed to assess the conditions for a completely auto-ID supply chain, where information flow starts when the 
processor grabs a tree and detects the tag previously applied, acquiring all the related information and, if available, the cutting instructions provided by the digital forest inventory.

\section{Conclusions}

RFID UHF tags proved to be suitable for marking standing trees for biannual periods. If the expected permanence in the forest is about 1 year, simple tag models with light cases should be preferred. They are easier to apply, have a lower unitary cost, and can therefore be used as disposable items, further simplifying their application at supply chain level. Furthermore, in the case of an integrated auto-ID value chain, a single model can adapt to several steps, such as automatic application with forest machines. Finally, the small size and mass of tags with simple cases makes them more acceptable for sawmill byproduct consumers. If the planned permanence in the forest is longer than 1 year, robust tags with strong protective cases will provide a more reliable solution. Nevertheless, due to their higher unitary cost compared to the simple models, these tags should be applied on high-value roundwood, or for the identification of batches of timber products, otherwise their cost will exceed the economic benefit provided. These tags should be always recovered at the end of the value chain (e.g., at the sawmill), and reused in the supply chain for as many cycles as possible. Recovering the tags from the logs prior to sawmill processing also guarantees the removal of any metal screws or rivets from the timber, avoiding damage to the sharp tools.

Regardless the type of tag used, it is important to consider the effect of tree growth over time and minimize the damage that this can cause to the tags attached. In general terms, attachment to the tree should be done in a single position (single staple or screw) rather than two or more, allowing the tag a certain degree of free movement that accommodates tree growth.

Funding: This work has been conducted within the framework of the project SLOPE receiving funding from the European Union's Seventh Framework Programme for research, technological development and demonstration under the NMP.2013.3.0-2 (Grant number 604129).

Acknowledgments: The author wish to thank Flavio Dalla Valle for the invaluable support in the field study. Thanks are also due to three anonymous reviewers and the academic editor for their contribution to improve the paper quality and to Whitney Choat for language proof-reading.

Conflicts of Interest: The author declares no conflict of interest.

\section{References}

1. Luvisi, A.; Panattoni, A.; Bandinelli, R.; Rinaldelli, E.; Pagano, M.; Triolo, E. Ultra-High Frequency transponders in grapevine: A tool for traceability of plants and treatments in viticulture. Biosyst. Eng. 2012, 113, 129-139. [CrossRef]

2. Ilie-Zudor, E.; Kemény, Z.; Van Blommestein, F.; Monostori, L.; Van Der Meulen, A. A survey of applications and requirements of unique identification systems and RFID techniques. Comput. Ind. 2011, 62, 227-252. [CrossRef]

3. Appelhanz, S.; Osburg, V.-S.; Toporowski, W.; Schumann, M. Traceability System for Capturing, Processing and Providing Consumer-relevant Information about Wood Products: System Solution and its Economic Feasibility. J. Clean Prod. 2016, 110, 132-148. [CrossRef]

4. Laporte, J.; Vandenhaute, M.; Wilson, S.; Meunier, Q.; Soh Ndeh, J. Traceability-A Management Tool for Enterprises and Governments; FAO-FLEGT: Rome, Italy, 2016.

5. Figorilli, S.; Antonucci, F.; Costa, C.; Pallottino, F.; Raso, L.; Castiglione, M.; Pinci, E.; Del Vecchio, D.; Colle, G.; Proto, A.R.; et al. A Blockchain Implementation Prototype for the Electronic Open Source Traceability of Wood along the Whole Supply Chain. Sensors 2018, 18, 3133. [CrossRef] [PubMed]

6. Marchi, E.; Chung, W.; Visser, R.; Abbas, D.; Nordfjell, T.; Mederski, P.S.; McEwan, A.; Brink, M.; Laschi, A. Sustainable Forest Operations (SFO): A new paradigm in a changing world and climate. Sci. Total. Environ. 2018, 634, 1385-1397. [CrossRef] [PubMed]

7. Picchio, R.; Proto, A.R.; Civitarese, V.; Di Marzio, N.; Latterini, F. Recent Contributions of Some Fields of the Electronics in Development of Forest Operations Technologies. Electron. 2019, 8, 1465. [CrossRef] 
8. Mohamed, N.; Garoot, A.H.; Hazza, Z.M. A case study on impacts of RFID adoption in tree inventory management. In Proceedings of the 2009 2nd IEEE International Conference on Computer Science and Information Technology; Institute of Electrical and Electronics Engineers (IEEE): Piscataway, NJ, USA, 2009; pp. 624-628.

9. Kaakkurivaara, N. Possibilities of using barcode and RFID technology in Thai timber industry. Maejo Int. J. Sci. Technol. 2019, 13, 29-41.

10. Picchi, G.; Kühmaier, M.; Diaz Marques, J.D.D. Survival Test of RFID UHF Tags in Timber Harvesting Operations. Croat. J. For. Eng. 2015, 36, 165-174.

11. Ferrer, G.; Dew, N.; Apte, U. When is RFID right for your service? Int. J. Prod. Econ. 2010, 124, 414-425. [CrossRef]

12. Zhu, X.; Mukhopadhyay, S.K.; Kurata, H. A review of RFID technology and its managerial applications in different industries. J. Eng. Technol. Manag. 2012, 29, 152-167. [CrossRef]

13. Korten, S.; Kaul, C. Application of RFID (Radio Frequency Identification) in the Timber Supply Chain. Croat. J. For. Eng. 2008, 29, 85-94.

14. Häkli, J.; Jaakkola, K.; Pursula, P.; Huusko, M.; Nummila, K. UHF RFID based tracking of logs in the forest industry. In Proceedings of the 2010 IEEE International Conference on RFID (IEEE RFID 2010); Institute of Electrical and Electronics Engineers (IEEE): Piscataway, NJ, USA, 2010; pp. 245-251.

15. Kaul, C. Auto-ID in timber supply chain-identifying single logs using RFID tags. In Proceedings of the FORMEC conference, Padova, Italy, 11-14 July 2010; pp. 1-7.

16. Björk, A.; Erlandsson, M.; Häkli, J.; Jaakkola, K.; Nilsson, Å.; Nummila, K.; Puntanen, V.; Sirkka, A. Monitoring environmental performance of the forestry supply chain using RFID. Comput. Ind. 2011, 62, 830-841.

17. Pichler, G.; Lopez, J.A.P.; Picchi, G.; Nolan, E.; Kastner, M.; Stampfer, K.; Kühmaier, M. Comparison of remote sensing based RFID and standard tree marking for timber harvesting. Comput. Electron. Agric. 2017, 140, 214-226. [CrossRef]

18. Zimbelman, E.G.; Keefe, R.F. Real-time positioning in logging: Effects of forest stand characteristics, topography, and line-of-sight obstructions on GNSS-RF transponder accuracy and radio signal propagation. PLOS ONE 2018, 13, e0191017. [CrossRef] [PubMed]

19. Sandak, J.; Sandak, A.; Marrazza, S.; Picchi, G. Development of a Sensorized Timber Processor Head Prototype-Part 1: Sensors Description and Hardware Integration. Croat. J. For. Eng. 2019, 40, $25-37$.

20. Kaakkurivaara, T.; Kaakkurivaara, N. Comparison of radio frequency identification tag housings in a tropical forestry work environment. Aust. For. 2019, 82, 181-188. [CrossRef]

21. Gjerdrum, P. Rfid Tags Applied for Tracing Timber in the Forest Products Chain. In Proceedings of the 5 th meeting of the Nordic-Baltic Network in Wood Material Science and Engineering (WSE), Copenhagen, Denmark, 1-2 October 2009; pp. 109-114. 